\title{
ARTIGOS
}

Submetido em 30.10.2016. Aprovado em 19.06.2017

Avaliado pelo processo de double blind Review. Editor Científico: Cesar Alexandre de Souza

DOI: http://dx.doi.org/10.1590/So034-759020170606

\section{TECNOLOGIA DA INFORMAÇÃO VERDE: ESTUDO À LUZ DA TEORIA CRENÇA-AÇÃO-RESULTADO}

\author{
Green Information Technology: A study in light of Belief-Action-Outcome theory \\ Tecnología de la Información Verde: Estudio basado en la teoría Creencia-Acción- \\ Resultado
}

\begin{abstract}
RESUMO
Este estudo pretende compreender como as pressões institucionais e as crenças ambientais de gestores influenciam a adoção da Tecnologia da Informação Verde (TI Verde); para tanto, foi utilizado como aporte teórico o modelo Crença-Ação-Resultado (Belief-Action-Outcome [BAO]). A pesquisa é qualitativa, e os sujeitos da pesquisa são 10 gestores de instituições de ensino superior (IES). A coleta de dados foi realizada por entrevistas e um checklist com práticas de TI Verde. A análise das entrevistas foi realizada por análise de conteúdo, e as respostas do checklist foram avaliadas pela frequência. Os resultados revelam que a pressão institucional mais relacionada com a adoção da TI Verde, pelos entrevistados, é a mimética. Sobre as crenças ambientais, oito gestores demonstraram preocupações com tais questões. Contudo, apenas três gestores tomaram iniciativas próprias; os demais entrevistados reportaram vivenciar barreiras como disfunções da burocracia e falta de apoio da alta gerência ao proporem ações relacionadas a TI Verde.
\end{abstract}

PALAVRAS-CHAVE | Tecnologia da Informação Verde, Crença-Ação-Resultado, gestores de Tecnologia da Informação, instituições de ensino superior, pesquisa qualitativa.

GABRIELA FIGUEIREDO DIAS

gabrielafigr.dias@gmail.com Doutoranda em Administração pela Universidade Federal do Rio Grande do Norte - Natal - RN, Brasil

\section{ANATÁLIA SARAIVA MARTINS RAMOS}

anataliasaraiva@gmail.com

Professora da Universidade Federal do Rio Grande do Norte, Centro de Ciências Sociais

Aplicadas - Natal-RN, Brasil

\section{RÔMULO ANDRADE DE SOUZA NETO}

romuloasneto@gmail.com Doutorando em Administração pela Universidade Federal do Rio Grande do Norte - Natal-RN, Brasil

EVANGELINA DE MELLO BASTOS evangelinabastos@gmail.com Mestre em Administração pela Universidade Federal do Rio Grande do Norte - Natal-RN, Brasil

\section{ABSTRACT}

This study aims to understand how institutional pressures and managers' environmental beliefs influence the adoption of Green Information Technology (Green IT). The theoretical framework of the Belief-Action-Outcome model is used. In a qualitative research approach, data on 10 university IT managers were collected through interviews and a checklist of Green IT practices. Content analysis on the interviews was performed and the responses to the checklist were analyzed by frequency. Analysis results show that the institutional pressure most related to the adoption of Green IT for the interviewees is mimetic. Regarding environmental beliefs, while eight managers expressed concerns about environmental issues, only three reported their own initiatives. Other respondents said they faced barriers such as bureaucratic dysfunctions and lack of management support to propose actions related to Green IT.

KEYWORDS I Green Information Technology, Belief-Action-Outcome, Information Technoloyg managers, universities, qualitative research.

\section{RESUMEN}

Este estudio pretende comprender cómo las presiones institucionales y creencias ambientales de gestores influyen en la adopción de la Tecnología de la Información Verde (TI Verde). Se adoptó como soporte teórico el modelo Creencia-Acción-Resultado. La investigación es cualitativa y los sujetos son diez gestores de $\mathrm{TI}$ de instituciones de enseñanza superior. La recolección de datos se realizó por entrevistas y una lista de verificación con prácticas de TI Verde. El análisis de las entrevistas se realizó por medio del análisis de contenido y las respuestas de la lista de verificación se evaluaron por la frecuencia. Los resultados revelan que la presión institucional más relacionada con la adopción de la TI Verde, por los entrevistados, es la mimética. Sobre las creencias ambientales, ocho gestores mostraron preocupación con dichas cuestiones, no obstante, sólo tres tomaron sus propias iniciativas, los otros entrevistados reportaron enfrentar obstáculos, como las disfunciones burocráticas y la falta de apoyo de la dirección, al proponer acciones relacionadas con TI Verde.

PALABRAS CLAVE / Tecnología de la Información Verde, Creencia-Acción-Resultado, Gestores de Tecnología de la Información, instituciones de enseñanza superior, investigación cualitativa. 


\section{INTRODUÇÃO}

O objetivo deste artigo é compreender como as pressões institucionais e as crenças ambientais de gestores influenciam a adoção da TI Verde. Atualmente, a rápida difusão da tecnologia da informação (TI) gera diversos benefícios para sociedade e organizações. Contudo, esse rápido crescimento, associado à obsolescência planejada, provoca graves impactos ambientais e desperta a preocupação da sociedade e do governo, os quais passam a exigir uma postura mais sustentável das organizações (Chen, Watson, Boudreau, \& Karahanna, 2011; Lunardi, Alves, \& Sales, 2014; Murugesan, 2008). Uma solução encontrada para atender essas exigências é a adoção de TI Verde em sistemas e processos organizacionais.

A TI Verde é um conjunto de práticas ambientalmente responsáveis associadas à utilização da TI (Murugesan, 2008). Chou e Chou (2012) afirmam que, além de promover a sustentabilidade do planeta, essas práticas podem gerar benefícios para as organizações, como redução de gastos e melhoria da imagem organizacional. Assim, entende-se que a adoção da TI Verde é oportuna para os diversos tipos de organizações atuantes na sociedade.

Segundo a revisão bibliométrica realizada por Machado, Ramos e Nunes (2015) na base de dados Web of Science, o modelo da Crença-Ação-Resultado (BAO - Belief-Action-Outcome), proposto por Melville (2010), é a fundamentação teórica com maior impacto científico e a mais citada pelos pesquisadores da área de adoção da TI Verde (por ex.: Chen et al., 2011; Gholami, Sulaiman, Ramayah, \& Molla, 2013; Mithas, Kunthia, \& Roy, 2010; Molla, Abareshi, \& Cooper, 2014). Tal modelo permite a investigação de como a percepção individual sobre as inovações tecnológicas pode influenciar o desenvolvimento sustentável.

Apesar da influência do modelo BAO nas pesquisas sobre TI Verde, não identificamos pesquisas sobre os motivadores da TI Verde que utilizem esse modelo, no contexto brasileiro, segundo a busca realizada no Portal de Periódicos Capes. Consideramos que uma investigação sobre adoção da TI Verde no Brasil com aporte teórico do BAO pode contribuir para novas descobertas sobre o tema em âmbito nacional, uma vez que a teoria permite a investigação de aspectos considerados pela literatura científica como importantes na adoção das práticas de TI Verde, tais como: as crenças ambientais, o contexto sociopolítico e as pressões institucionais (Chen et al., 2011; Gholami et al., 2013; Mithas et al., 2010; Molla et al., 2014; Salles, Alves, Dolci, \& Lunardi, 2016). Diante desse contexto, este trabalho pretende responder à seguinte pergunta: Como as crenças dos gestores de $\mathrm{Tl}$ e as pressões institucionais podem influenciar a adoção da TI Verde?

Sob o ponto de vista teórico, pretende-se, com os resultados desta pesquisa, ajudar no reconhecimento de motivadores da adoção da TI Verde. Em termos de relevância prática, se comprovada a influência das crenças ambientais e das pressões institucionais, poderão ser planejados programas de conscientização e incentivo a inciativas de TI Verde. Ademais, as práticas de TI Verde adotadas e os benefícios evidenciados nas organizações investigadas poderão servir de exemplo e estímulo para implementação ou aperfeiçoamento de práticas de TI Verde em outras organizações.

\section{REFERENCIAL TEÓRICO}

\section{TI Verde - Conceito}

A TI Verde refere-se às iniciativas e programas que estão diretamente ou indiretamente relacionados à sustentabilidade ambiental nas organizações (Jenkin, Webster, \& McShane, 2011). Para Murugesan (2008), a “TI Verde refere-se à parte sustentável da TI” (p. 25), que envolve a fabricação, uso e descarte de computadores, servidores e subsistemas associados de maneira correta a fim de diminuir ou extinguir os impactos ambientais.

Murugesan (2008) e Lunardi, Simões, e Frio (2014) também apresentam a TI Verde como um conjunto de práticas ambientalmente responsáveis associadas à utilização da TI representadas por: conscientização do pessoal, adoção de políticas ambientais, eficiência energética, datacenter verde, virtualização, descarte responsável, reutilização e reciclagem, conformidade com a regulamentação ambiental, construção de prédios verdes, contratação de fornecedores verdes e compra de produtos com selos verdes.

\section{Crença-Ação-Resultado (BAO) e TI/SI Verde}

De acordo com os estudos de Melville (2010), existem três classes que influenciam a sustentabilidade: o estado cognitivo do indivíduo, as ações dos indivíduos e das organizações, e os resultados do desempenho ambiental e financeiro da organização. Esses três fenômenos compreendem as questões micro e macro organizacionais citadas no modelo Micro-Macro da Teoria da Ação (Coleman, 1986).

O modelo Micro-Macro mostra como as preferências individuais (nível micro) podem influenciar a estrutura social (nível macro) (Coleman, 1986). Dessa forma, Melville (2010), com 
base no modelo Micro-Macro, desenvolveu o modelo BAO (Figura 1), que integra elementos do nível micro (indivíduos) com os elementos do nível macro (sociedade, ambiente natural, organizações). 0 modelo BAO permite a investigação de como a percepção individual sobre as inovações tecnológicas pode influenciar o desenvolvimento sustentável.

Figura 1. Modelo Crença-Ação-Resultado para o contexto da TI e sustentabilidade

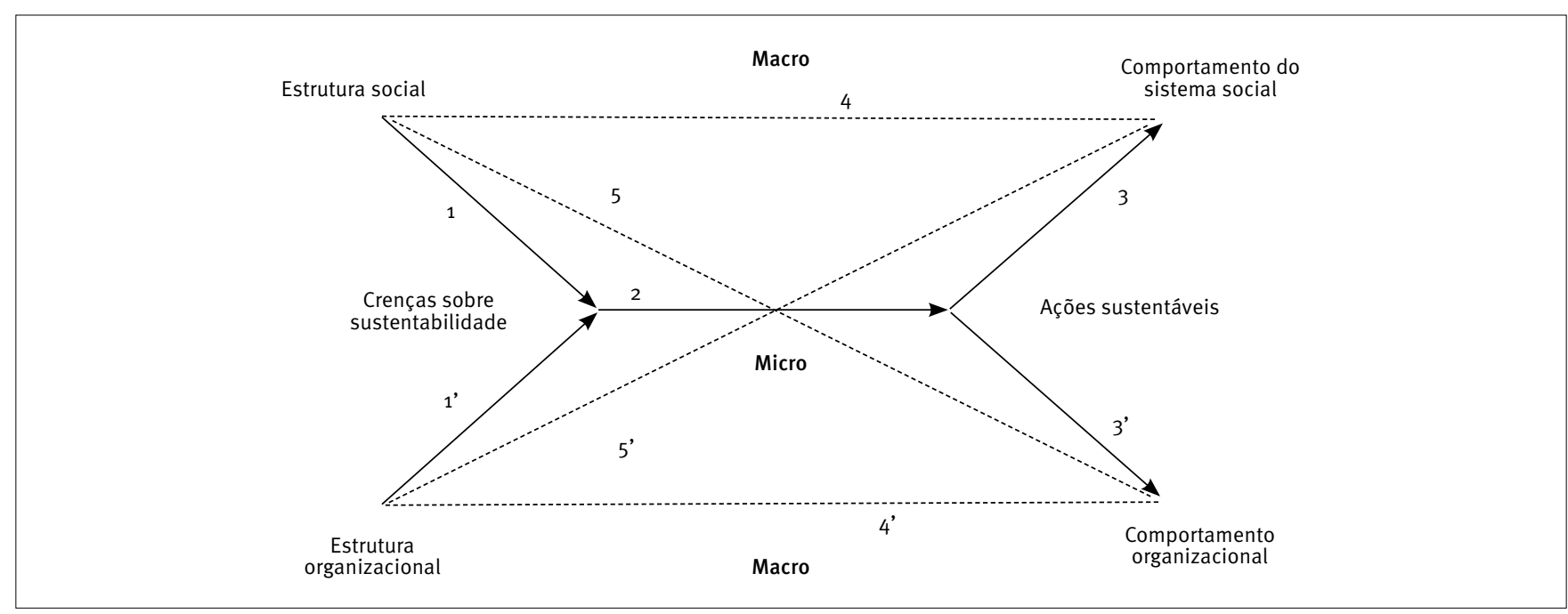

Fonte: Melville (2010) adaptado de Coleman (1986).

Como observado na Figura 1, Melville (2010) foi além da estrutura social prevista por Coleman (1986) e adicionou um antecedente chamado de estrutura organizacional no seu modelo. Como consequência, adicionou-se um novo resultado: o comportamento organizacional. O autor também incluiu as relações 4 e 5 , que conectam as variáveis do nível macro, permitindo investigar as organizações como agentes homogêneos, sem a participação dos indivíduos (Melville, 2010).

A partir da proposta de Melville (2010), surgiram pesquisas (por ex.: Gholami et al., 2013; Mithas et al., 2010; Molla et al., 2014) que utilizaram o BAO como base para realização de investigações acerca da TI Verde. Existem outras teorias que estudam o comportamento humano no contexto da adoção de inovações tecnológicas, tais como: Teoria da Ação Racional (TRA), Teoria Motivacional (TAM) e suas derivações (Gholami et al., 2013). Entretanto, ao realizarem pesquisas sobre os antecedentes da adoção da TI Verde, Mithas et al. (2010), Gholami et al. (2013) e Molla et al. (2014) decidiram adotar o BAO, sob a justificativa de que o modelo sugere que as crenças ambientais são influenciadas pelo contexto sociopolítico dos campos organizacionais. Tais campos são a base subjacente para a criação de processos organizacionais e ações individuais e coletivas em relação à TI Verde. Ademais, ao realizar uma análise da trajetória dos estudos sobre TI Verde, Machado et al. (2015) afirmaram que o modelo proposto por Melville (2010) aparece como o artigo científico com maior impacto na área.

O presente trabalho utilizará como base para criação de modelo de pesquisa o estudo realizado por Gholami et al. (2013). Esse modelo foi escolhido dado que seus autores se basearam no modelo de Melville (2010), que proporciona uma visão holística da adoção da TI Verde. A partir da BAO, Gholami et al. (2013) sugeriram um novo modelo com teorias específicas para estudar os microfatores (atitude e considerações sobre consequências futuras - CFC) e os macrofatores (pressão institucional). Além disso, o modelo permite a verificação das práticas de TI Verde implementadas e a identificação dos resultados gerados para a organização. Esse modelo é composto por cinco constructos: pressão institucional, atitude, CFC, adoção da TI/SI Verde e desempenho ambiental.

A pressão institucional é originada da Teoria Institucional, que se concentra nos aspectos mais profundos e resilientes da estrutura social. Essa teoria defende que, devido às suas características sociais e culturais, as empresas passam por um processo pelo qual suas estruturas (regras, normas e rotinas) se tornam condizentes e semelhantes com o ambiente externo. Isso explica como as organizações se tornam isomórficas, adotando práticas homogêneas que são consideradas legítimas dentro do sistema social (DiMaggio \& Powell, 1983).

A pressão institucional isomórfica se divide em três pilares: coercitivo, normativo e mimético (DiMaggio \& Powell, 
1983). A pressão coercitiva advém de autoridades reguladoras e parceiros da cadeia de abastecimento. A pressão normativa acontece quando a organização é pressionada a agir de maneira específica devido à cultura da sociedade local. A pressão mimética origina-se das empresas concorrentes, ou seja, à medida que outras organizações adotam a TI/SI Verde, os benefícios dessa implantação são percebidos pelas demais empresas do mercado (Chen et al., 2011; Gholami et al., 2013). Gholami et al. (2013) optaram por abordar apenas as pressões coercitiva e mimética.

0 constructo atitude refere-se à avaliação positiva ou negativa de um indivíduo ao realizar determinado tipo de comportamento (Ajzen, 1991). No estudo de Gholami et al. (2013), esse constructo possibilita a investigação do quanto os gestores estão interessados na adoção da TI Verde. Os referidos autores justificam a sua inclusão porque as atitudes dos gestores influenciam as iniciativas e mudanças organizacionais.

O constructo CFC tem como base os estudos de Strathman, Gleicher, Boninger, e Edwards (1994) e Joireman, Vanlange, e Vanvugt (2004), os quais revelam que pessoas com baixo CFC valorizam os resultados imediatos do seu comportamento; já pessoas com um alto CFC estimam uma grande importância para as consequências futuras do seu comportamento. Segundo a pesquisa de Srathman et al. (1994), pessoas com alto índice de CFC se preocupam mais com como as suas ações presentes podem influenciar futuramente a sua saúde pessoal e o meio ambiente. A pesquisa de Joireman et al. (2004), que relacionou a preferência do uso de transporte público e o CFC, concluiu que as pessoas com um maior nível de CFC optavam pelo uso do transporte público, visto que essa opção implicava poluir menos o meio ambiente. Esse constructo também foi confirmado na pesquisa de Gholami et al. (2013), pois os gerentes com um CFC alto adotavam com mais facilidade a TI Verde no ambiente de trabalho.

$\mathrm{O}$ constructo sobre adoção da TI/SI Verde originou-se de Chen et al. (2011), que utilizaram, para identificação das ações de TI Verde, as seguintes categorias: adoção de TI/SI Verde para prevenção da poluição (redução de emissões de gases tóxicos, do desperdício de materiais, do uso de materiais tóxicos), adoção de TI/SI Verde para gerenciamento de produtos (aquisição e distribuição de materiais de modo ambientalmente responsável), e adoção de TI/SI Verde no cotidiano da empresa (ferramentas de colaboração on-line, trabalho em localidades flexíveis utilizando a internet, incentivo da menor utilização de papel) (Gholami et al., 2013).

Por fim, para determinar os itens do constructo do desempenho ambiental que pretendem explicar como a adoção da TI/SI Verde pode influenciar o desempenho ambiental da empresa, Gholami et al. (2013) basearam-se na pesquisa de
Melnyk, Sroufe, e Calantone (2003). O desempenho foi medido por meio da percepção do gestor sobre os seguintes benefícios: certificação ambiental, redução de resíduos, redução de emissões, reciclagem, melhoria na conformidade ambiental, melhoria na imagem corporativa, preservação do ambiente e compromisso social (Gholami et al., 2013).

Ao final da sua pesquisa, Gholami et al. (2013) destacaram, como principais resultados, a influência positiva da pressão coercitiva e da CFC na adoção da TI Verde. Contudo, os resultados não sugeriram influência da pressão mimética nesse processo. Sobre o constructo desempenho ambiental da organização, foi verificado que a adoção da TI Verde gera resultados em longo prazo. No que se refere às pressões institucionais, o resultado apresentado corrobora em parte os achados de Chen et al. (2011), que utilizaram a Teoria Institucional para investigar a adoção da TI Verde, e chegaram à conclusão de que as pressões coercitiva e mimética influenciam de maneira significativa a adoção de tecnologias verdes.

Mithas et al. (2010) também utilizaram o modelo BAO para investigar a implementação da TI Verde nas organizações. Os resultados revelaram que o comprometimento da alta direção é um aspecto importante na percepção sobre a importância da TI Verde e pode influenciar positivamente os investimentos na adoção de tecnologias sustentáveis. Essa adoção também foi relacionada com reduções de gastos com energia elétrica. Continuando as pesquisas apoiadas no modelo BAO, Molla et al. (2014) analisaram como as organizações e a disponibilidade de informação contribuem para a formação de crenças e atitudes dos profissionais de $\mathrm{Tl}$ em relação à TI Verde. Os resultados mostraram que o campo organizacional e a disponibilidade da informação contribuem para a crença e atitude dos funcionários em relação à TI Verde, e os levam a praticar ações sustentáveis dentro das organizações.

Molla e Abareshi (2011) utilizaram como arcabouço teórico a Teoria Motivacional e pesquisaram como as motivações sustentáveis da organização influenciam a adoção da TI Verde. Os resultados mostraram que a ecoeficiência e ecoeficácia são motivos que influenciam a adoção de tecnologias ambientalmente responsáveis, pois estas contribuem para a eficiência energética da organização, bem como para a redução da poluição. Mshira, Akman, e Mshira (2014) investigaram a adoção da TI Verde com base na Teoria da Ação Racional (Theory of Reasoned Action, TRA) junto aos funcionários do setor público e concluíram que as crenças ambientais influenciam as ações associadas à TI Verde, no ambiente de trabalho, assim como esses profissionais enfrentam dificuldades para implementação da TI Verde devido às disfunções da burocracia. 
Em âmbito nacional, Salles et al. (2016) examinaram as motivações para adoção TI Verde e, em três estudos de casos, foi encontrado que as dimensões econômica e legal são as que mais motivam a adoção de tecnologias verdes, enquanto as dimensões social e ambiental possuem menos peso na adoção. Também foi revelado que os benefícios ambientais são consequências das mudanças realizadas em função dos aspectos econômicos da empresa.

\section{Modelo da pesquisa}

Após análises dos estudos realizados sobre o tema e para atender o objetivo geral da pesquisa, optamos por utilizar como arcabouço teórico o modelo de pesquisa proposto por Gholami et al. (2013). A fim de adaptar o modelo de pesquisa para o âmbito nacional e adequá-lo à metodologia desta pesquisa, foram sugeridas algumas modificações.

Na presente pesquisa, foram mantidos os microfatores que tratam de atitude e CFC. Também foram mantidos os macrofatores, utilizando as pressões institucionais. Entretanto, diferentemente de Gholami et al. (2013), e conforme sugere o artigo seminal de
DiMaggio e Powell (1983), foram investigados os três tipos de pressões: normativa, coercitiva e mimética.

O constructo sobre adoção de TI/SI Verde, proposto por Gholami et al. (2013), foi adaptado para melhor aplicação no âmbito nacional e melhor condução do método de pesquisa. Para tanto, foi utilizada uma lista de verificação (checklist) com base no conjunto de práticas de TI Verde identificado por Lunardi et al. (2014), que mapearam as 37 práticas de TI Verde mais adotadas em 111 organizações brasileiras, distribuídas em sete categorias temáticas práticas de conscientização, datacenter verde, descarte e reciclagem, fontes alternativas de energia, hardware, impressão e software.

Por fim, após revisão dos estudos de Salles et al. (2016), Chou e Chou (2012), Bose e Luo (2012), Lunardi et al. (2014) e Cai, Chen, e Bose (2012), a categoria desempenho organizacional será substituída por benefícios percebidos, a fim de identificar se, do ponto de vista dos gestores, as práticas de TI Verde geram vantagens para as organizações. A Figura 2 mostra o modelo gráfico da pesquisa. Há três categorias (macrofatores, microfatores e benefícios percebidos) e cinco subcategorias (pressão coercitiva, pressão normativa, pressão mimética, CFC e benefícios percebidos), e sete categorias temáticas do checklist.

\section{Figura 2. Modelo gráfico da pesquisa}

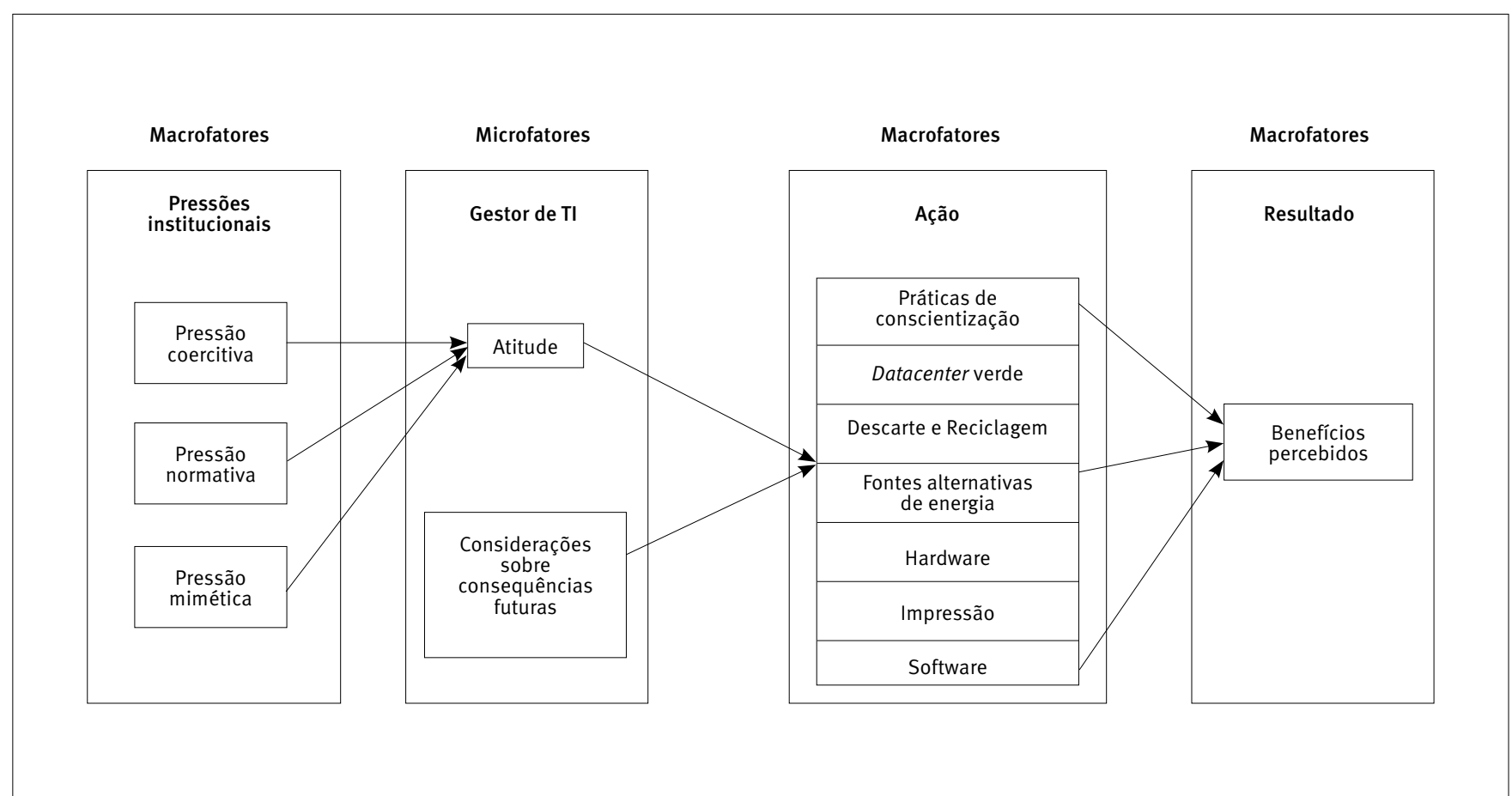

Fonte: Adaptado de Gholami et al. (2013) e Lunardi et al. (2014).

Na seção de análise e discussão dos resultados, cada categoria será retomada e relacionada com as informações coletadas e analisadas. 


\section{METODOLOGIA}

A presente pesquisa é classificada, quanto aos fins, como descritiva com abordagem qualitativa. Conforme Myers (2009), os dados qualitativos ajudam a entender as pessoas, suas motivações e ações, bem como o contexto no qual elas trabalham e vivem.

Os sujeitos desta pesquisa foram gestores de TI de IES do Brasil. A escolha desses sujeitos justifica-se pelo fato de que possuem conhecimento específico na área de TI, e o cargo ocupado exige que eles estejam permanentemente cientes da situação da TI na organização. Quanto ao campo de estudo, foram escolhidas IES porque as suas ações, frequentemente, servem de exemplo para os outros tipos de organizações que procuram nas universidades boas práticas para replicação (Tauchen \& Brandlin, 2006).

Para identificar os sujeitos, foram adotadas duas estratégias. A primeira foi a amostragem não aleatória por acessibilidade, que, na pesquisa qualitativa, é comum devido à acessibilidade geográfica ou pela possibilidade de contato imediato (Miles, Huberman, \& Saldaña, 2014). Assim, inicialmente foram pesquisados os contatos dos gestores de TI nos sites das IES localizadas em um estado brasileiro específico. A segunda estratégia foi a bola de neve, que se deu diante da dificuldade de acesso aos gestores apenas com a primeira estratégia e permitiu contato com gestores de IES de outros estados. A bola de neve é uma técnica de amostragem em que o pesquisador pede aos participantes referência de novos informantes que possuam as características desejadas (Flick, 2009). Conforme Coleman (1958), “esta técnica de amostragem é como a de um bom repórter que rastreia as 'pistas' de uma pessoa para outra” (p. 29).

O critério para o encerramento da coleta foi a saturação teórica, ou seja, quando não surgiram novas informações nos dados coletados (Glaser \& Strauss, 2006). A saturação teórica deste trabalho foi percebida na análise (codificação) das primeiras oito entrevistas realizadas. Verificou-se que a maioria dos códigos foi criada na análise das primeiras quatro entrevistas - nas outras quatro, foram criados poucos códigos novos. Para confirmar a saturação teórica, foram realizadas mais duas entrevistas que já estavam agendadas. Após análise dessas duas entrevistas, foi observado que não surgiram novas informações. Assim, ao final da décima entrevista, optou-se pela suspensão da coleta de dados.

Os dados foram coletados por meio de entrevistas semiestruturadas. Devido às dificuldades de acesso aos entrevistados, além das entrevistas realizadas pessoalmente, foram realizadas seis entrevistas on-line por meio de chamada de voz de maneira síncrona (Flick, 2009). No início da coleta de dados, a fim de preservar a privacidade dos entrevistados, foram seguidas as seguintes recomendações éticas de Creswell (2010): explicação do propósito da pesquisa, solicitação da permissão para gravação das falas, entrega e assinatura de termos de consentimento e confidencialidade, e armazenamento dos dados em local seguro.

0 roteiro da entrevista foi desenvolvido com base no questionário da pesquisa de Gholami et al. (2013) e nos resultados dos estudos de Chou e Chou (2012), Bose e Luo (2012), Lunardi et al. (2014) e Cai et al. (2012). Com o propósito de validação e aperfeiçoamento do instrumento, o roteiro foi apresentado a pesquisadores de um grupo de pesquisa cadastrado no CNPq, e depois passou por duas entrevistas piloto (Flick, 2009). A versão final do roteiro é composta por 10 perguntas (Quadro 1) referentes às subcategorias preestabelecidas no modelo inicial (Figura 2). Também foi aplicado um checklist com a escala de três pontos (1) adotado, (2) parcialmente adotado e (3) não adotado - para identificar as práticas de TI Verde adotadas pelas IES. Este foi elaborado com base nas práticas mapeadas por Lunardi et al. (2014), conforme mencionado. As entrevistas com os gestores ocorreram no período de 2 de março a 20 de março de 2015 , com duração de 20 a 45 minutos. Após o término da coleta de dados, todas as entrevistas foram transcritas. 0 material empírico totalizou 82 páginas.

Para análise dos dados coletados pelas entrevistas, foi utilizada a análise de conteúdo categorial. Segundo Bardin (2011), esse tipo de análise consiste na segmentação do texto em diversas unidades e categorias conforme reagrupamentos analíticos. Para auxiliar esse processo, foi utilizado o software de análise de dados qualitativos NVivo ${ }^{\circledR} 10$.

A análise de conteúdo foi realizada em três etapas: análise inicial, exploração do material e tratamento dos resultados. $\mathrm{Na}$ análise inicial, foi realizada uma leitura flutuante de todo o texto gerado no processo de transcrição. Na fase exploração do material, foi realizada a codificação e categorização dos dados brutos do texto (Bardin, 2011). Seguindo as recomendações de Saldaña (2009), o processo de codificação foi realizado em duas fases: codificação inicial e codificação focalizada. Os códigos que não estavam preestabelecidos no modelo proposto por esta pesquisa emergiram a partir das falas dos entrevistados. A codificação inicial gerou 216 códigos provisórios, os quais passaram pela codificação focalizada para maior refinamento e hierarquização dos códigos. Após essa rodada de codificação, restaram 41 códigos, que foram alocados em oito subcategorias e posteriormente distribuídas nas três categorias preestabelecidas. Essa segunda etapa está ilustrada na árvore de codificação (Figura 3). 


\section{Quadro 1. Roteiro de entrevista}

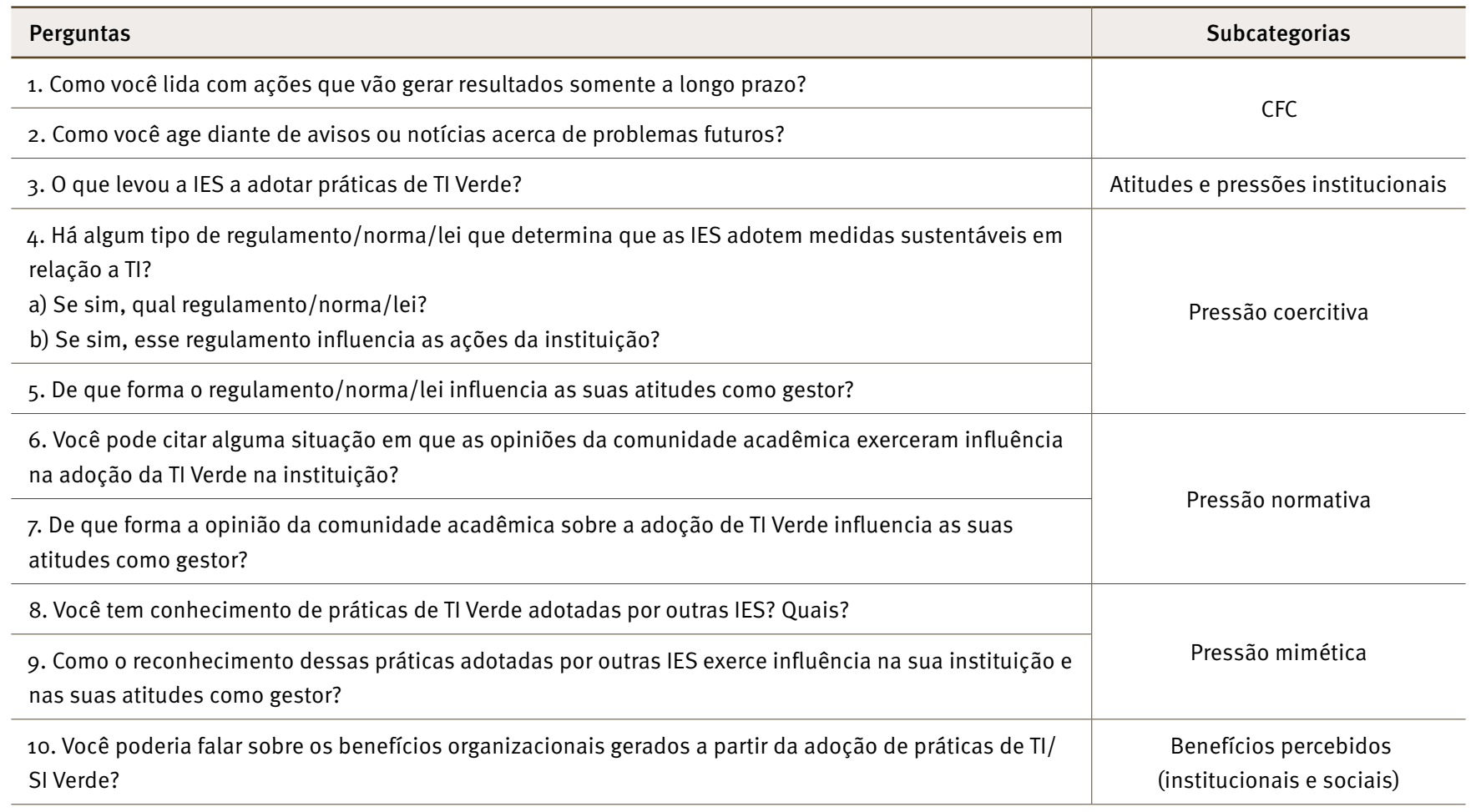

Figura 3. Árvore de codificação

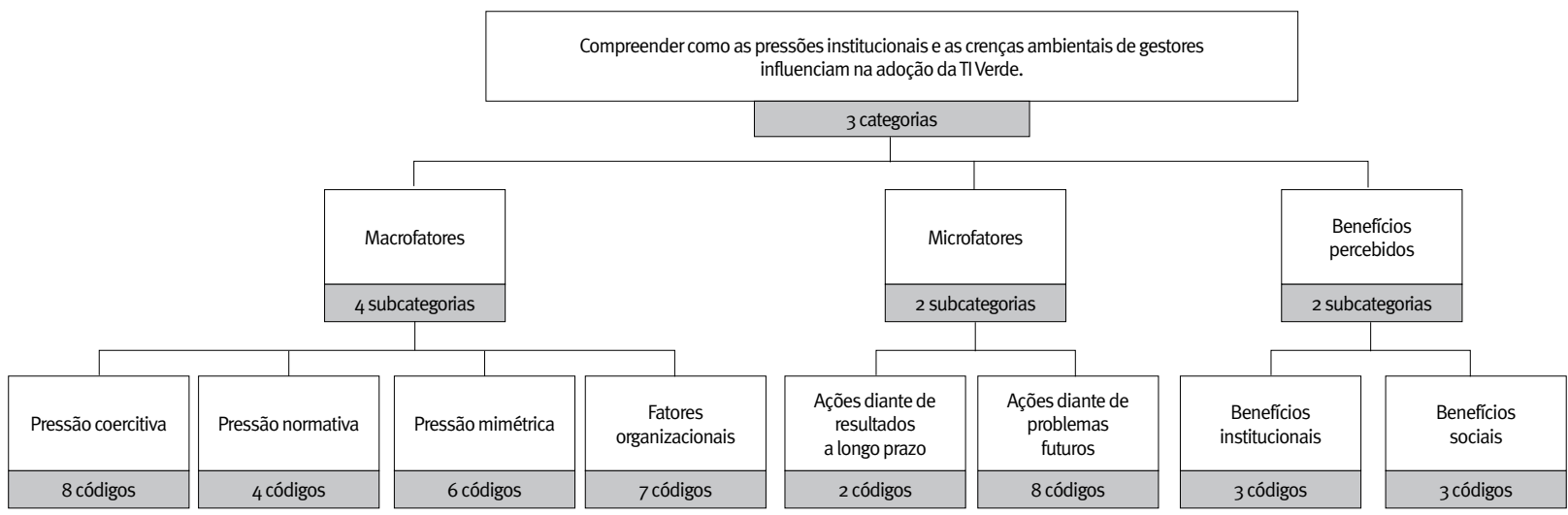

A última etapa, o tratamento dos resultados, consistiu na realização de inferências e interpretação das entrevistas. A fim de facilitar a compreensão dos resultados, após a análise realizada com auxílio do $\mathrm{NVivo}^{\circledR} 10$ foram geradas representações esquemáticas possibilitando a ilustração das relações entre categorias, subcategorias e códigos. Essas representações esquemáticas são apresentadas no início de cada subseção da análise e discussão dos resultados. As categorias são representadas por círculos, as subcategorias, por hexágonos, e os códigos, por quadrados.

Quanto ao tratamento dos dados coletados pelo checklist, foi utilizada a análise de frequência da adoção das práticas de TI Verde, seguindo a escala de adoção apresentada no checklist. Conforme as recomendações de Creswell (2010), os resultados 
gerados nessa fase da análise serviram para complementar os resultados obtidos na análise predominantemente qualitativa. A fim de sintetizar os procedimentos metodológicos, foi criado um protocolo de pesquisa, apresentado na Figura 4.

\section{Figura 4. Protocolo de pesquisa}

\begin{tabular}{|c|c|c|c|c|c|}
\hline \multicolumn{6}{|c|}{ Objetivo da pesquisa } \\
\hline \multicolumn{6}{|c|}{ Compreender como as pressões institucionais e as crenças ambientais de gestores influenciam na adoção da TI Verde. } \\
\hline \multicolumn{6}{|c|}{ (2) } \\
\hline Macrofatores & Atitude & \multicolumn{2}{|c|}{ Microfatores } & Práticas de TI Verde & Benefícios percebidos \\
\hline \multicolumn{6}{|c|}{ ২ל } \\
\hline \multicolumn{6}{|c|}{ Elaboração e validação de instrumento de coleta } \\
\hline $\begin{array}{l}\text { Roteiro de entrevista } \\
\text { e Chou, 2012, Bose e }\end{array}$ & $\begin{array}{l}\text { 13, Chou } \\
\text { al., 2012) }\end{array}$ & \multicolumn{2}{|c|}{$\begin{array}{l}\text { Checklist das práticas de TI Verde } \\
\quad \text { (Lunardi, Alves et al., 2014) }\end{array}$} & \multicolumn{2}{|c|}{$\begin{array}{l}\text { Validação feita por pesquisadores de um grupo } \\
\text { de pesquisa e duas entrevistas piloto (Flick, 2009) }\end{array}$} \\
\hline \multicolumn{6}{|c|}{$\sqrt{3}$} \\
\hline \multicolumn{6}{|c|}{ Identificação dos sujeitos } \\
\hline \multicolumn{3}{|c|}{ Amostragem não aleatória por acessibilidade (Miles et al., 2014) } & \multicolumn{3}{|c|}{ Bola de neve (Coleman, 1958) } \\
\hline \multicolumn{6}{|c|}{ Coleta de dados } \\
\hline \multicolumn{3}{|c|}{ Entrevistas semiestruturadas e aplicação do checklist } & \multicolumn{3}{|c|}{$\begin{array}{c}\text { Suspensão das entrevistas devido à saturação teórica (não foram gerados } \\
\text { novos códigos a partir da } 8^{\text {a }} \text { entrevista) (Glasser \&Strauss, 2006) }\end{array}$} \\
\hline \multicolumn{6}{|c|}{ Análise de dados } \\
\hline \multicolumn{3}{|c|}{$\begin{array}{l}\text { Análise de conteúdo categorial (41 códigos, } 8 \text { subcategorias e } 3 \text { categorias) } \\
\qquad \text { (Bardin, 2004, Saldaña, 2009) }\end{array}$} & \multicolumn{3}{|c|}{ Análise de frequência dos dados do checklist } \\
\hline
\end{tabular}

\section{ANÁLISE E DISCUSSÃO DOS RESULTADOS}

\section{Caracterização dos indivíduos}

Os participantes desta pesquisa foram gestores de TI com vinculação em IES públicas e privadas do Brasil. O Quadro 2 apresenta as características pessoais dos 10 entrevistados, tais como: nomes fictícios, escolaridade, tipo de instituição onde trabalham e estado.

Como apresentado no Quadro 2, os sujeitos da pesquisa são nove homens e uma mulher. Em relação à faixa etária, os entrevistados têm entre 30 e 56 anos, e a maioria se encontra na faixa entre 41 e 45 anos. Em relação ao nível de escolaridade, nove gestores possuem pós-graduação e um possui graduação. A maioria dos entrevistados residia na região Nordeste do País, sendo um vinculado a uma IES da Paraíba (PB), e seis gestores de seis IES localizadas no Rio Grande do Norte (RN). Os outros três entrevistados estavam vinculados a IES nas regiões Sul (Rio Grande do Sul - RS), Sudeste (Rio de Janeiro - RJ) e Centro-Oeste (Goiás - GO) do Brasil.

\section{Macrofatores}

$\mathrm{Na}$ categoria macrofatores, foram identificadas as três subcategorias - pressão coercitiva, pressão normativa e pressão mimética. Além destas, durante a codificação, foi identificado outro macrofator previsto por Melville (2010), que foi nomeado de fatores organizacionais e gerou uma nova subcategoria. A representação esquemática da categoria (Figura 5) ilustra o resultado da análise.

Quadro 2. Caracterização dos sujeitos

\begin{tabular}{l|c|c|c}
\hline Nome fictício & Escolaridade & Tipo de instituição & Estado \\
\hline Allan & Mestrado & Pública & RN \\
\hline André & Mestrado & Pública & RN \\
\hline Ariano & Mestrado & Pública & RN \\
\hline Caio & Especialização & Privada & RN \\
\hline Carlos & Mestrado & Pública & GO \\
\hline Gustavo & Doutorado & Pública & RJ \\
\hline Joana & Especialização & Pública & RS \\
\hline Nathan & Mestrado & Pública & RN \\
\hline Paulo & Mestrado & Pública & PB \\
\hline William & Graduação & Privada & RN \\
\hline
\end{tabular}




\section{Figura 5. Representação esquemática dos macrofatores}

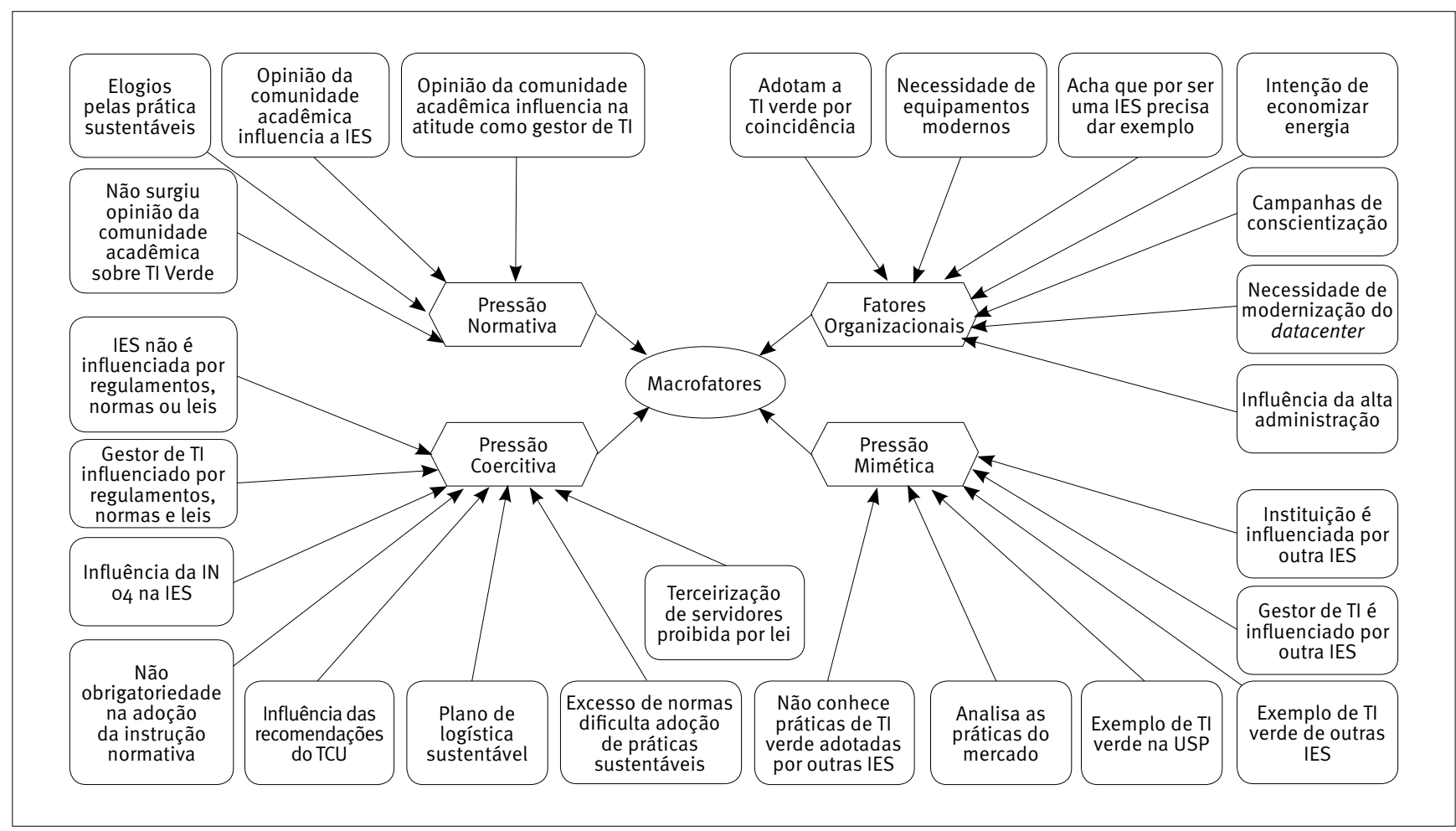

Quando questionados sobre a influência de regulamentos, normas e leis (pressão coercitiva), os 10 entrevistados alegaram pouco conhecimento sobre leis acerca da adoção da TI Verde. No entanto, seis entrevistados afirmaram ter conhecimento sobre instruções normativas propostas pelo Ministério do Planejamento relacionadas com administração da $\mathrm{Tl}$, mas estas funcionavam apenas como sugestão. Esses aspectos podem ser percebidos na fala de Ariano: "Não, que eu saiba não. A nível de governo federal existem algumas iniciativas, de alguns órgãos de controle, mas que seja uma lei que todo mundo tem que seguir não conheço”. Também na fala de William: "Não sei. Regulamento ou lei... eu acho que não... que nos obrigue a usar, acho que não". Apesar de não existir obrigatoriedade na adoção das instruções normativas do governo federal, quatro entrevistados afirmaram que a instituição e o trabalho deles como gestores de TI eram influenciados por essas instruções. A principal influência era sentida no processo de compra de produtos eletrônicos sustentáveis.

Os resultados apresentados assemelham-se em parte aos de Salles et al. (2016), que realizaram estudos de casos com três empresas nacionais e chegaram à conclusão de que, no Brasil, não há uma regulamentação específica para TI Verde, mas outras leis relacionadas à $\mathrm{TI}$ faziam com que as empresas adotassem práticas sustentáveis. Por outro lado, Chen et al. (2011) e Gholami et al. (2013), que investigaram a adoção da TI Verde em âmbito internacional, afirmaram que as organizações pesquisadas eram influenciadas pela pressão coercitiva, devido à existência de leis mais específicas aplicadas à TI Verde. Assim, no caso do Brasil, há pressão coercitiva, mas de maneira moderada, porque as leis são mais difusas.

Sobre a influência da opinião da comunidade acadêmica (pressão normativa), apenas três entrevistados relataram haver esse tipo de influência nas IES. Entre esses, foram relatadas situações em que a comunidade acadêmica interviu na adoção de energias renováveis nos prédios dos campi.

Os próprios alunos de certa forma pressionaram para que toda iluminação lá do ambiente fosse trocada por uma iluminação que fosse renovável, com fontes de energia renovável. Por isso eu citei aquele exemplo dos postes que foram substituídos por postes com energia solar. (Paulo)

As falas desses três entrevistados estão de acordo com os resultados das pesquisas de Chen et al. (2011) e Gholami et al. (2013), que constataram a influência da pressão normativa na adoção da TI Verde. Apesar do relato positivo desses três entrevistados sobre a pressão normativa, os outros sete gestores afirmaram que não conheciam situações em que a opinião da comunidade acadêmica influenciou a adoção de práticas sustentáveis associadas à TI. Esse 
último resultado é corroborado pelo estudo de Salles et al. (2016), que também foi realizado no Brasil, o qual afirma que as dimensões sociais, entre elas a opinião da sociedade, apresentam pouca importância na adoção da TI Verde.

No que se refere à influência mimética, seis entrevistados deram respostas positivas sobre esse tipo de influência. Como podemos notar na fala de William: “A gente sempre lê... boa prática é sempre bom imitar, então a gente sempre procura estar conversando, saber o que estão fazendo...". Também na fala de Ariano: “A USP tá preservando o ambiente e eu quero trazer essa mesma coisa pra cá, essa mesma preocupação e iniciativa pra cá...”. Esse resultado corrobora os estudos de Salles et al. (2016) e Chen et al. (2011), pois ambos afirmam que, ao observarem os bons resultados conseguidos pelos concorrentes, as instituições demonstram maior motivação para adoção da TI Verde.

Os outros quatro gestores afirmaram que as IES em que trabalhavam não sofriam influência de ações realizadas por outras instituições. Esses relatos estão de acordo com as conclusões de Gholami et al. (2013), onde foi achado que a pressão mimética não influencia a adoção da TI Verde.

$\mathrm{Na}$ categoria macrofatores, emergiu a subcategoria fatores organizacionais, que contém sete códigos advindos das falas de nove entrevistados. A emergência da subcategoria fatores organizacionais é apoiada pelo estudo de Melville (2010), que defende que, além das pressões da estrutura social, as organizações e os gestores também são influenciados pela estrutura organizacional.

Os fatores organizacionais mais citados foram a necessidade de modernização dos equipamentos e dos datacenters e a economia de energia que os equipamentos verdes geralmente proporcionam.

A gente fez o projeto para modernizar o datacenter com dois grandes objetivos; um era ter um ambiente mais seguro onde as informações da instituição estivessem de maneira segura e organizada e o outro era ter realmente eficiência energética. (Allan)

Outros fatores organizacionais influentes na adoção da TI Verde citados pelos gestores foram exigências da alta administração e campanhas de conscientização realizadas no campus. A informação de que a alta administração influencia a adoção da TI Verde é corroborada pelos resultados da pesquisa de Mithas et al. (2010). Em relação à influência das campanhas de conscientização, esse resultado é confirmado pela pesquisa de Molla et al. (2014).

Outra motivação exposta por dois entrevistados é que eles acham que, por ser uma IES, esta tem o dever de adotar práticas sustentáveis, a fim de servir de exemplo para alunos e outras organizações. Esse resultado é corroborado por Tauchen e Brandlin (2006), justamente quando afirmam que as universidades podem e devem trabalhar em prol de um ambiente mais sustentável, a fim de dar exemplo para seus alunos e as demais organizações inseridas na sociedade.

Além disso, os entrevistados citaram que outra motivação foi a necessidade organizacional coincidir com a TI Verde, ou seja, a princípio, não existia a intenção de adoção de práticas verdes associadas à TI, porém, ao tentar suprir uma necessidade da organização, essas práticas sustentáveis foram adotadas. Podemos notar esse aspecto na fala de Carlos: "Pois é, essas coisas todas são feitas, mas não exatamente com a preocupação verde, [mas] porque é a forma mais eficiente de fazer as coisas".

\section{Microfatores}

No processo de análise de dados, a partir da categoria preestabelecida microfatores e na Teoria CFC, foram geradas duas subcategorias baseadas nas falas dos entrevistados: ações diante de projetos em longo prazo e ações diante de problemas futuros. Ao final da codificação, foi gerada uma representação esquemática da categoria microfatores, apresentada na Figura 6.

Conforme a Figura 6, quando questionados sobre ações diante de projetos em longo prazo, os entrevistados demonstraram duas posturas distintas: a disposição para trabalhar com projetos em longo prazo e a dificuldade de lidar com projetos em longo prazo. Oito entrevistados se demonstraram dispostos a trabalhar com projetos em longo prazo, e demonstraram nas suas falas os seguintes aspectos: motivação para investir em projetos em longo prazo, exemplos de projeto em longo prazo e planos futuros.

No processo de análise, foram identificadas falas que demonstravam motivação para investir em projetos em longo prazo, como a de Gustavo: “A motivação é que você consegue colher lá na frente os frutos disso. Mesmo que não seja uma coisa imediata. Se você planejar hoje, você consegue amanhã ter algum benefício desse planejamento". Também a fala de Joana: "Porque a gente não pode trabalhar só a curto prazo, senão nós estamos perdidos, se a gente só enxergar um palmo na frente do nariz, onde é que fica o futuro?".

Ainda em relação aos projetos de longo prazo, dois entrevistados relataram dificuldade de lidar com horizontes mais largos. André relata: "Eu tenho dificuldade de fazer planos muito distantes, que não sejam um pouco mais próximos. Isso é uma questão pessoal mesmo. Eu tenho uma certa dificuldade em fazer esse tipo de planejamento ... Se eu for olhar para um horizonte distante sem ter nada próximo a que me apegar, eu tenho extrema dificuldade". No mesmo sentido, Nathan expõe sua dificuldade: "Dificilmente eu tenho uma reação de imediato 
com relação a isso. Muitas vezes aquele aviso precisa tomar uma proporção bem maior para que eu tenha uma reação". Logo, os dois entrevistados preferem dar prioridade para ações com resultados mais imediatos.

\section{Figura 6. Representação esquemática dos microfatores}

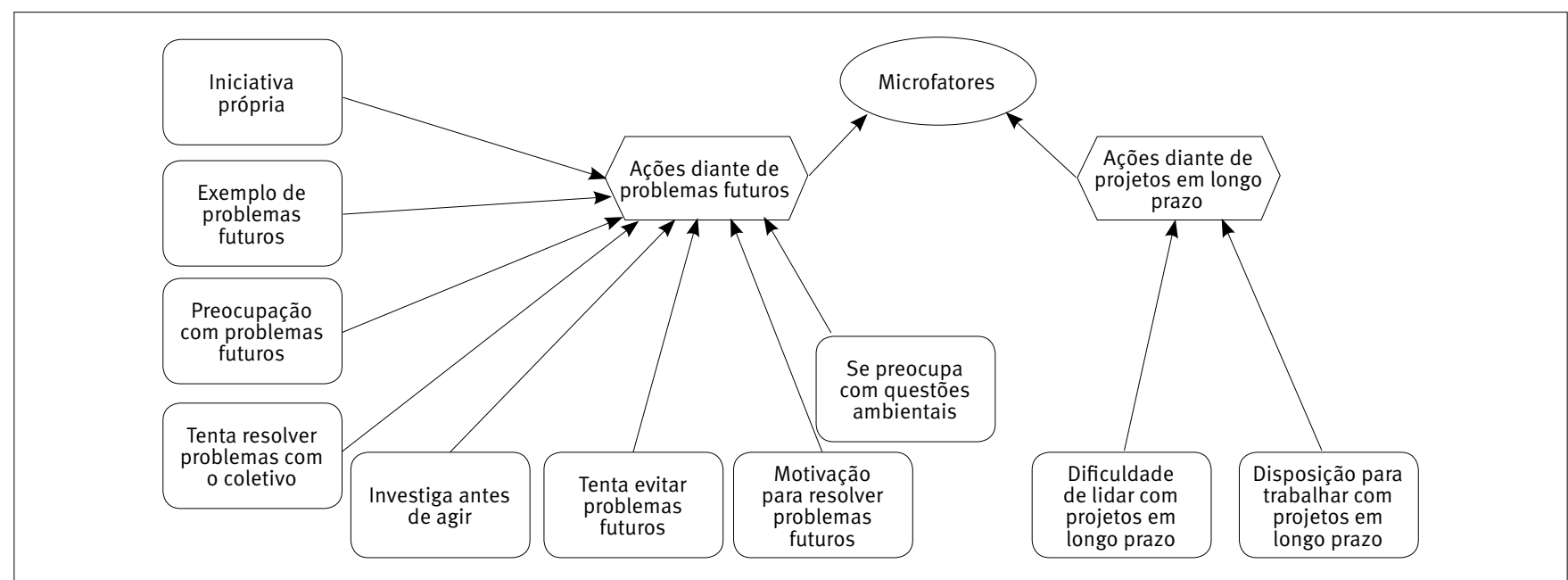

Os oito entrevistados que, na subcategoria anterior, demonstraram disposição para trabalhar com resultados em longo prazo foram os mesmos que demonstraram preocupação com problemas futuros e motivação para resolvê-los e evitá-los. Eles relataram que realizam investigações sobre os possíveis problemas futuros e citaram exemplos de ações pessoais diante de avisos sobre problemas futuros. Isso pode ser observado na fala de Joana: "Se o assunto me interessa, eu procuro dar uma olhada, procurar outras fontes, tentar entender o que é, para poder ter uma posição". Outros entrevistados também relataram suas motivações para resolver problemas futuros, como notamos na fala de Paulo, que explica por que se preocupa com possíveis problemas que possam ocorrer na IES: “De certa maneira, caso haja algum problema, são mais de 2.500 pessoas que serão impactadas, então eu sempre fui muito preocupado, não apenas comigo, mas com o ambiente em que eu estou" (Paulo).

André e Nathan, que, na subcategoria anterior, demonstraram dificuldade de trabalhar com resultados em longo prazo, quando questionados sobre as suas ações diante de problemas futuros, responderam que tentam resolver o problema de maneira coletiva, como pode ser observado na fala abaixo.

Aquela história de que o problema apareceu, você sabia e não falou para ninguém, ou não debateu, ou não deu oportunidade de debater, ou seja, o contrário disso, eu avisei a todo mundo, a gente teve a oportunidade de debater e nada foi feito... (André)
Os entrevistados não foram questionados sobre a preocupação com questões ambientais, entretanto, corroborando as pesquisas de Strathman et al. (1994), Joireman et al. (2004) e Gholami et al. (2013), quatro dos oito entrevistados que demonstraram disposição para trabalhar com resultados em longo prazo e preocupação com problemas futuros também demonstraram, nas suas falas, interesse e preocupação com as questões ambientais na vida pessoal e no ambiente de trabalho (Ariano, Caio, Gustavo e Joana).

Três entrevistados (Ariano, Caio e Gustavo) relataram iniciativa pessoal na adoção de práticas verdes associadas à TI. As iniciativas relatadas podem ser observadas na fala de Ariano: "A gente viu que tinha que tomar iniciativa, que não podia ficar esperando o próprio governo federal baixar uma medida obrigando a gente adotar ações sustentáveis". E na fala de Caio: “Na verdade não teve um consenso, não foram as pessoas, não foi o diretor, foi a gente mesmo - setor de TI - que resolveu fazer isso". Esse resultado corrobora o estudo de Mshira et al. (2014), que utilizou a Teoria da Ação Racional (TRA) para investigar a adoção da TI verde, e concluiu que as crenças pessoais podem influenciar as ações dos indivíduos no ambiente de trabalho.

Era esperado que os oito entrevistados que demonstraram disposição para trabalhar com resultados em longo prazo e preocupação com consequências futuras se mostrassem preocupados com questões ambientais. Contudo, de acordo com os resultados desta pesquisa, apenas três desses entrevistados tomaram iniciativas dentro da instituição associadas às tecnologias verdes. Entre esses três, Gustavo relatou que, apesar 
de tomar a iniciativa, não recebeu apoio da alta gestão, o que tornou a sua ação inviável. Joana e Paulo (que se demonstraram dispostos a trabalhar com problemas futuros) também expuseram dificuldades em adotar práticas sustentáveis devido às disfunções da burocracia. Esse último resultado é corroborado pela pesquisa de Mshira et al. (2014), que foi realizada em âmbito internacional e evidenciou que, em organizações públicas, as disfunções da burocracia são barreiras para adoção da TI Verde.

Na Figura 7, são apresentados os fatores influenciadores de cada um dos entrevistados.

Figura 7. Macro e microfatores

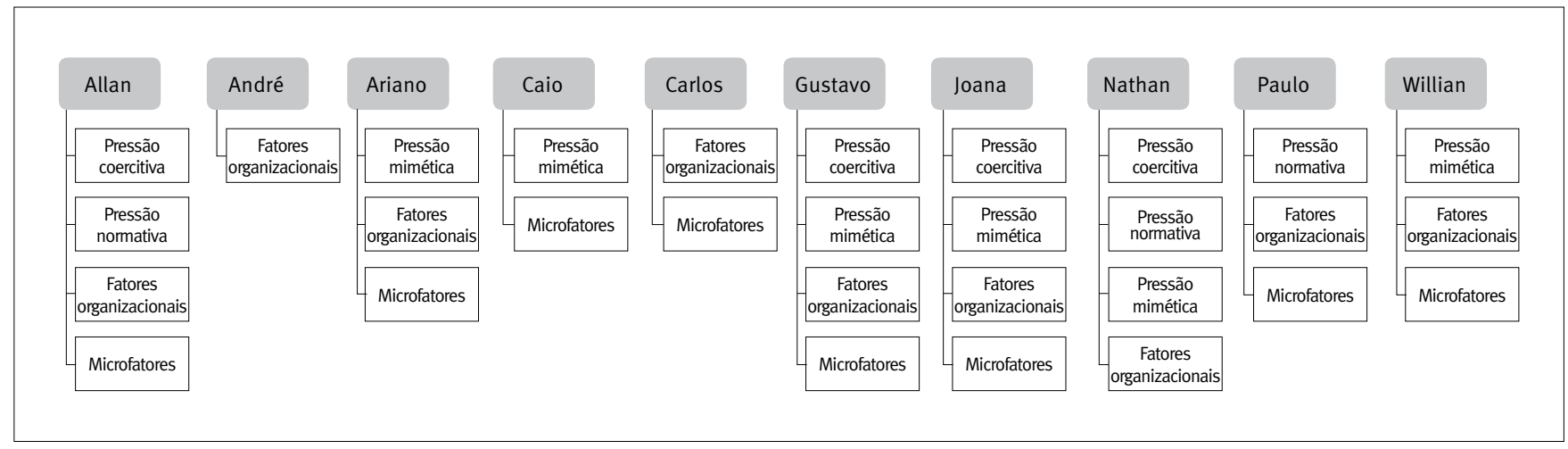

Corroborando os resultados apresentados, a Figura 7 mostra que os microfatores que possivelmente estimulam a preocupação com questões ambientais estão presentes na fala de oito entrevistados, mas apenas três gestores relataram iniciativa própria. Mostraram-se presentes com maior frequência os macrofatores pressão mimética e fatores organizacionais, mas as pressões coercitiva e normativa também foram identificadas nas falas de alguns gestores.

\section{Práticas de TI Verde}

A Tabela 1 apresenta de maneira sintética as frequências da adoção das práticas de TI Verde de cada uma das IES a que os entrevistados estão vinculados, bem como o porcentual dessas frequências.

Tabela 1. Frequências da adoção das práticas de TI Verde

\begin{tabular}{|c|c|c|c|c|c|c|}
\hline Entrevistados & \multicolumn{2}{|c|}{ Não adotado } & \multicolumn{2}{|c|}{ Parcialmente adotado } & \multicolumn{2}{|c|}{ Totalmente adotado } \\
\hline Allan & 17 & $45,90 \%$ & 9 & $24,30 \%$ & 11 & $29,70 \%$ \\
\hline André & 12 & $32,40 \%$ & 14 & $37,80 \%$ & 11 & $29,70 \%$ \\
\hline Ariano & 12 & $32,40 \%$ & 8 & $21,60 \%$ & 17 & $45,90 \%$ \\
\hline Gustavo & 22 & $59,50 \%$ & 11 & $29,70 \%$ & 4 & $10,80 \%$ \\
\hline Joana & 9 & $24,30 \%$ & 26 & $70,30 \%$ & 2 & $5,40 \%$ \\
\hline Nathan & 11 & $29,70 \%$ & 7 & $18,90 \%$ & 19 & $51,40 \%$ \\
\hline Paulo & 13 & $35,10 \%$ & 20 & $54,10 \%$ & 4 & $10,80 \%$ \\
\hline
\end{tabular}

Podemos observar que há uma maior frequência na adoção das práticas de TI Verde nas IES a que estão vinculados Ariano, Carlos, Nathan e William. Já nas IES dos entrevistados André, Joana e Paulo, há uma predominância da frequência parcial na adoção 
da TI Verde. Nas IES em que trabalham Allan, Caio e Gustavo, há menor frequência na adoção da TI Verde.

Observando a Figura 7 e a Tabela 1, nota-se que cada IES investigada tem uma frequência diferente de adoção das práticas de TI Verde, bem como todas são influenciadas por um conjunto diferente de fatores. A não homogeneidade dos resultados possivelmente se deu porque as IES investigadas estão inseridas em distintos contextos. De modo específico, sete das IES pesquisadas estão localizadas no Nordeste e, entre estas, duas são particulares e cinco são públicas. Já as outras três IES respondentes são públicas e estão localizadas em regiões diferentes do País. Como os entrevistados foram unânimes ao afirmarem ter pouco ou nenhum conhecimento sobre lei associada à TI Verde, outro aspecto que pode ter contribuído para essa não homogeneidade é a falta de regulamentação mais consistente do governo no que se refere à adoção da TI Verde. Apesar de sofrerem influência de diferentes conjuntos de fatores, podemos observar, na seção seguinte, que todos os entrevistados mencionaram benefícios institucionais e oito citaram benefícios sociais originados da adoção da TI Verde.

\section{Benefícios percebidos}

Durante as entrevistas, foram realizadas perguntas acerca de benefícios organizacionais. Contudo, no decorrer das entrevistas, emergiram, nas falas dos entrevistados, três benefícios relacionados à sociedade: doação de equipamentos para outras instituições, contribuição para aprendizagem dos alunos e benefícios ambientais. Assim, seguindo o modelo de Melville (2010), que afirma que as ações institucionais geram resultados para as estruturas organizacional e social, dentro da categoria benefícios percebidos, foram criadas, com base nas falas dos entrevistados, duas subcategorias: benefícios institucionais e benefícios sociais. Ao final do processo de codificação, foi gerada uma representação esquemática da categoria (Figura 8).

\section{Figura 8. Representação esquemática dos benefícios percebidos}

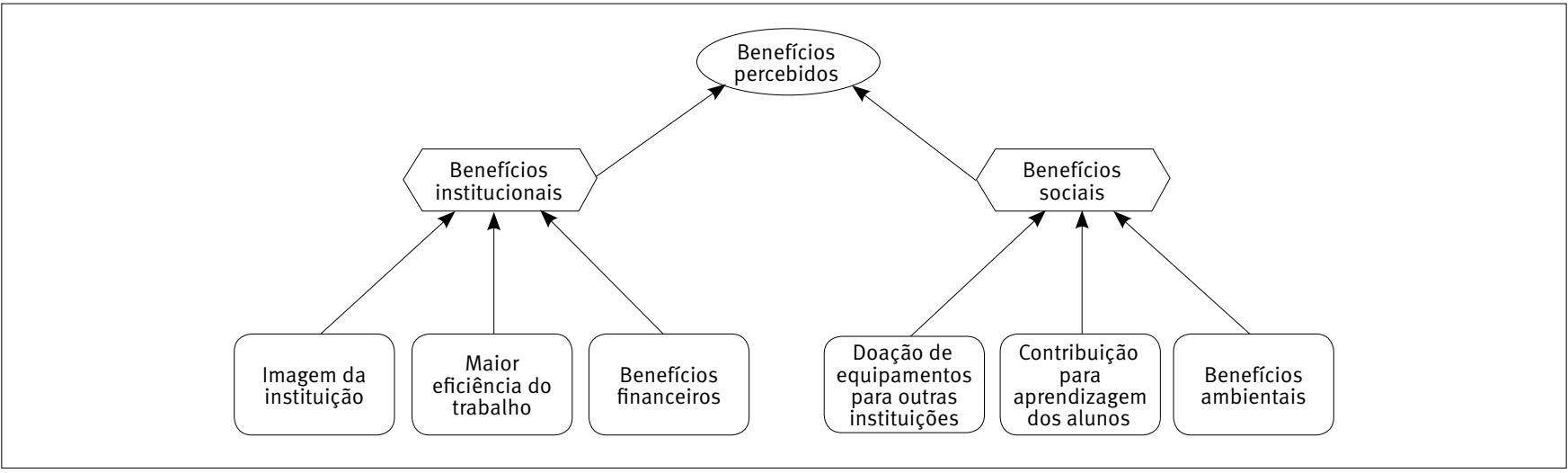

Em relação aos benefícios institucionais, os 10 entrevistados afirmaram perceber benefícios financeiros relacionados à adoção das práticas de TI Verde. Para esses gestores, geralmente a adoção de tecnologias verdes gera economia de energia, além das práticas de reutilização e reciclagem que podem diminuir os custos com aquisição de TI, bem como gerar benefícios sociais como doações de computadores para instituições carentes.

Esse resultado está de acordo com a pesquisa de Cai et al. (2012), que afirma que a redução de custos é o benefício gerado pela TI Verde mais fácil de identificar. Esse resultado também é corroborado pelas pesquisas de Chou e Chou (2012), Bose e Luo (2012), Lunardi et al. (2014) e Salles et al. (2016), que também tiveram a redução de gastos evidenciada nas suas investigações.

Outro benefício citado por seis entrevistados foi a melhoria da eficiência no trabalho resultante da adoção de tecnologias verdes. $O$ benefício é percebido na fala de Gustavo: “A virtualização de servidores tem vantagens não só verdes, como para na hora de você organizar o seu sistema, oferece a virtualização de servidores, e oferece outras facilidades...". Esse resultado corrobora as pesquisas de Murugesan (2008) e Bose e Luo (2012), que afirmam que a virtualização, além de trazer benefícios ambientais, também é responsável pela redução de custos, economia de tempo e agilidade no processamento de informações.

Outro benefício percebido citado pelos entrevistados foi a melhoria da imagem da instituição perante a sociedade.

E a própria universidade dá o exemplo para o mercado. Muitas coisas que a gente desenvolve aqui na universidade são seguidas. Às vezes o próprio mercado nos cobra isso “E aí? Como é 
que vocês tão resolvendo esse problema aqui na universidade?". (Ariano)

Esse resultado é confirmado pelos estudos de Murugesan (2008), Chou e Chou (2012), Lunardi et al. (2014) e Gholami et al. (2013), que também acharam que um dos benefícios gerados pela adoção da TI Verde é a promoção da imagem corporativa.

Em relação aos benefícios sociais, foram gerados três códigos: doações de equipamentos para outras instituições, contribuição na aprendizagem dos alunos e benefícios ambientais. Entre os 10 entrevistados, apenas dois gestores não relataram benefícios sociais. O benefício social mais citado (cinco entrevistados) foi a doação de equipamentos eletrônicos para outras instituições. Nas instituições em que trabalham, realizam doações de computadores usados para outras instituições que necessitam desse material.

Doação também a gente faz. Às vezes a gente vai fazer uma doação, a gente pega um ou dois ou três computadores para formar um. Apenas para deixar funcionando, coloca memória suficiente, coloca sistema operacional básico pra ele não ficar tão lento. (Caio)

Normalmente, os computadores doados, apesar de não serem novos, ainda estão em condições de atender à necessidade das instituições para onde são doados. Esse resultado está de acordo com os estudos de Murugesan (2008), que fala sobre a possibilidade de doação de equipamentos que ainda estão em condições de uso.

Outro benefício social que emergiu na fala de três entrevistados foi a contribuição para aprendizagem dos alunos. Com a instalação de tecnologias ambientalmente amigáveis dentro da instituição, são realizadas aulas ou palestras a respeito do assunto, bem como a prática do descarte do lixo eletrônico de maneira correta pode gerar material de estudo para os alunos.

Acho que o benefício maior é você poder de certa forma junto com os alunos mostrar o que pode ser conseguido com práticas verdes ... Eles podem utilizar esse lixo eletrônico de forma didática, então nós promovemos aqui competições de robótica, os próprios alunos constroem robôs e muitas vezes com esses equipamentos que foram para o descarte. (Paulo)

Este resultado confirma a pesquisa de Tauchen e Brandlin (2006), que defende que as IES devem adotar ações em prol do desenvolvimento sustentável, pois estas são responsáveis pela formação de profissionais que devem chegar no mercado de trabalho com consciência ambiental.

Sobre os benefícios ambientais, foram citados por quatro entrevistados: a redução do consumo de insumos e a diminuição da poluição. Esses resultados corroboram as pesquisas de Gholami et al. (2013), Lunardi et al. (2014), e Molla e Abareshi (2011), que afirmam que a adoção de práticas de TI Verde podem contribuir para redução da poluição e desenvolvimento sustentável do planeta.

Após a análise e discussão dos resultados, devido às categorias que emergiram dos relatos dos gestores, o modelo de pesquisa inicial apresentado no referencial teórico foi modificado. Foi adicionada (na categoria macrofatores) a subcategoria fatores organizacionais, e a categoria benefícios percebidos foi dividida em benefícios sociais e organizacionais. As categorias pressão coercitiva, pressão normativa e CFC + iniciativa pessoal ficaram tracejadas a fim de demonstrar um baixo número de citações entre os entrevistados. As mudanças citadas podem ser observadas na Figura 9.

Figura 9. Modelo gráfico da pesquisa modificado

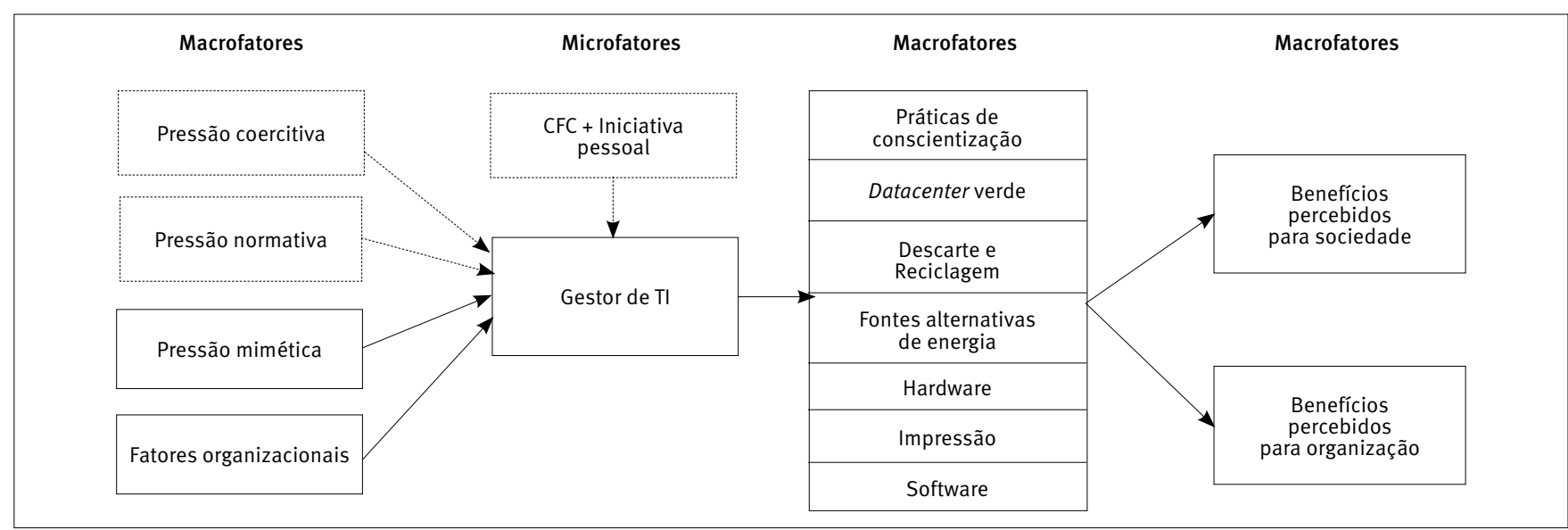




\section{CONCLUSÃO}

Podemos concluir que o objetivo da pesquisa foi atingido. Quanto aos macrofatores, verificamos que as subcategorias que receberam mais citações em relação à influência positiva na adoção da TI Verde foram pressão mimética e os fatores organizacionais. No que tange à pressão coercitiva, nenhum dos entrevistados conhecia leis específicas sobre TI Verde. Diante disso, sugerimos iniciativas mais consistentes do governo federal para melhorar a regulamentação das práticas de TI Verde. Sobre a influência da pressão normativa na adoção da TI Verde, apenas três gestores citaram esse aspecto nas suas falas. Assim, sugerimos, para as IES, a realização de ações de conscientização da comunidade acadêmica.

Quanto à influência dos microfatores, foi constatada a preocupação com questões ambientais na fala de oito gestores, todavia apenas três gestores relataram iniciativas próprias. Alguns gestores associaram as dificuldades na tomada de iniciativas com a falta de apoio da alta gestão e disfunções da burocracia. Diante disso, sugerimos que as organizações invistam na conscientização ambiental da alta gestão, bem como na desburocratização de alguns processos, a fim de que as IES se tornem um ambiente mais aberto para a recepção de sugestões e promoção de iniciativas no campo da sustentabilidade. Também sugerimos a realização de pesquisas futuras que investiguem a lacuna entre crença e adoção de prática na TI Verde, visto que nem todos os gestores que demonstraram preocupações ambientais tomaram iniciativas concretas.

Com relação à fundamentação teórica adotada, foram realizadas três modificações no modelo de Gholami et al. (2013) para apresentar todos os resultados encontrados da forma desejada. A primeira foi considerar as três pressões contidas na Teoria Institucional. A segunda foi adicionar o macrofator fatores organizacionais ao modelo, já que este emergiu com frequência nas falas dos entrevistados. A terceira foi dividir a categoria benefícios percebidos em benefícios sociais e benefícios organizacionais para separar e discutir melhor os resultados encontrados. As duas últimas modificações estavam previstas no modelo BAO proposto por Melville (2010). Sugerimos que pesquisas futuras sobre TI Verde validem o modelo proposto em outras realidades.

Em relação às limitações do trabalho, podemos citar a falta da diversificação dos sujeitos da pesquisa quanto ao gênero, tipo de IES, localização geográfica, e a não uniformização da coleta de dados, visto que foram realizadas entrevistas tanto presenciais quanto on-line.

\section{REFERÊNCIAS}

Ajzen, I. (1991). The theory of planned behavior. Organizational Behavior and Human Decision Processes, 50(2), 179-211. doi:10.1016/07495978(91)90020-T

Bardin, L. (2011). Análise de conteúdo ( $3^{\mathrm{a}}$ ed.) São Paulo, SP: Edições 70.

Bose, R., \& Luo, X. (2012). Green IT adoption: A process management approach. International Journal of Accounting and Information Management, 20(1), 63-77. doi:10.1108/18347641211201081

Cai, S., Chen, X., \& Bose, I. (2012). The many faces of green IT. International Journal of Business Data Communications and Networking, 8(2), 52-59. doi:10.4018/jbdcn.2012040104

Chen, A., Watson, R., Boudreau, M., \& Karahanna, E. (2011). An institutional perspective on the adoption of green IS \& IT. Australasian Journal of Information Systems, 17(1), 5-27. doi:10.3127/ajis.v17i1.572

Chou, D., \& Chou, A. (2012). Awareness of green IT and its value model. Computer Standards \& Interfaces, 34(5), 447-451. doi:10.1016/j. csi.2012.03.001

Coleman, J. (1958). Relational analysis: The study of social organizations with survey methods. Human Organization, 17(4), 28 36. doi:10.17730/humo.17.4.95604m67626oq8n7

Coleman, J. (1986). Social theory, social research, and a theory of action. American Journal of Sociology, 91(6),1309-1335. doi:10.1086/228423

Creswell, J. (2010). Projeto de pesquisa: Métodos qualitativo, quantitativo e misto ( $3^{\text {a }}$ ed.) Porto Alegre, RS: Artmed.

DiMaggio, P., \& Powell, W. (1983). The iron cage revisited: Institutional isomorphism and collective rationality in organizational fields. American Sociological Review, 48(2), 147-160.

Flick, U. (2009). Introdução a pesquisa qualitativa ( $3^{\mathrm{a}}$ ed.). Porto Alegre, RS: Artmed.

Gholami, R., Sulaiman, A., Ramayah, T., \& Molla, A. (2013). Senior managers' perception on green information systems adoption and environmental performance: Results from a field survey. Information \& Manegament, 50(7), 431-438. doi:10.1016/j.im.2013.01.004.

Glaser, B. \& Strauss, A. (2006). The discovery of grounded theory: Strategies for qualitative research. New Jersey, USA:AldineTransaction.

Jenkin, T., Webster, J., \& McShane, L. (2011). An agenda for 'green' information technology and systems research. Information and Organization, 21(1), 17-40. doi:10.1016/j.infoandorg.2010.09.003

Joireman, J., Vanlange, P., \& Vanvugt, M. (2004). Who cares about the environmental impact of cars? Those with an eye toward the future. Environment and Behavior, 36(2), 187-206. doi:10.1177/0013916503251476

Lunardi, G., Alves, A., \& Salles, A. (2014). Desenvolvimento de uma escala para avaliar o grau de utilização da tecnologia da informação verde pelas organizações. RAUSP-Revista de Administração da Universidade de São Paulo, 49(3), 591-605. doi:10.570o/rausp1170

Lunardi, G., Simões, R., \& Frio, R. (2014). TI Verde: Uma análise dos principais benefícios e práticas utilizadas pelas organizações. READRevista Eletrônica de Administração, 77(1), 1-30. doi:10.1590/S141323112014000100001 
Machado, P., Ramos, A., \& Nunes, B. (2015). Trajetória dos estudos de green IT/S. Anais do V ENADI - Encontro de Administração da Informação, Brasília, DF.

Melnyk, S., Sroufe, R., \& Calantone, R. (2003). Assessing the impact of environmental management systems on corporate and environmental performance. Journal of Operations Management, 21(3), 329-351. doi:10.1016/S0272-6963(02)00109-2

Melville, N. (2010). Information systems innovation for environmental sustainability. MIS Quarterly, 34(1), 1-21.

Miles, M. B., Huberman, A., \& Saldaña, J. (2014). Qualitative data analysis: A methods sourcebook (3rd ed.). Thousand Oaks, USA: Sage.

Mithas, S., Kunthia, J., \& Roy, P. (2010). Green information technology, energy efficiency, and profits: Evidence from an emerging economy. Proceedings of the 31st International Conference on Information Systems(ICIS), Saint Louis, USA. Recuperado de http://aisel. aisnet.org/cgi/viewcontent.cgi?article $=1009 \&$ context=icis2010_ submissions

Molla, A., \& Abareshi, A. (2011). Green IT adoption: A motivational perspective. Proceedings of the 15 st Pacific Asian conference on information systems (PACIS), Brisbane, Australia. Recuperado de http://aisel.aisnet.org/cgi/viewcontent.cgi?article=1136\&contex$\mathrm{t}=$ pacis2011

Molla, A., Abareshi, A., \& Cooper, V. (2014). Green IT beliefs and proenvironmental IT practices among IT professionals. Information Technology \& People, 27(2), 129-154. doi:10.1108/ITP-10-2012-0109.
Mshira, D., Akman, I., \& Mshira, A. (2014). Theory of reasoned action application for green information technology acceptance. Computers in Human Behavior, 36, 29-40. doi:10.1016/j.chb.2014.03.030

Murugesan, S. (2008). Harnessing green IT: Principles and practices. IEEE Computer Society, 10(1), 24-33. doi:10.1109/MITP.2008.10

Myers, M. (2009). Qualitative research in business \& management. London, UK: Sage.

Saldaña, J. (2009). The coding manual for qualitative researchers. London, UK: Sage.

Salles, A. C., Alves, A. P., Dolci, D., \& Lunardi, G. (2016). Tecnologia da informação verde: Um estudo sobre sua adoção nas organizações. RAC-Revista de Administração Contemporânea, 20(1), 41-63. doi:10.1590/1982-7849rac20161887

Strathman, A., Gleicher, F., Boninger, D., \& Edwards, C. (1994). The consideration of future consequences: Weighing immediate and distant outcomes of behavior. Journal of Personality and Social Psychology, 66(4), 742-752. doi:10.1037/0022-3514.66.4.742

Tauchen, J., \& Brandlin, L. (2006). A gestão ambiental em instituições de ensino superior: Modelo para implantação em campus universitário. Gestão \& Produção, 13(3), 503-515. doi:10.1590/S0104$530 X 2006000300012$ 